\title{
La transposición de la literatura y el teatro argentino del siglo XIX al cine del siglo XX: \\ El último centauro o la epopeya de Juan Moreira de Enrique Queirolo
}

\section{The transposition of literature and Argentine theater from the 19th century to cinema of the 20th century: EI último centauro o la epopeya de Juan Moreira of Enrique Queirolo}

\author{
Lía Noguera \\ CONICET/Universidad de Buenos Aires/ \\ Universidad Nacional de las Artes \\ lianoguera@yahoo.com.ar \\ ORCID ID: 0000-0002-0765-5160
}

\begin{abstract}
Resumen: A partir de la leyenda del gaucho argentino Juan Moreira, en el presente artículo nos proponemos analizar los diferentes atravesamientos artísticos que su cuerpo realiza desde fines del siglo XIX hasta principios del $\mathrm{XX}$ : de la novela a la arena del circo y del teatro al cine. Consideramos que en cada cruce y en cada nuevo soporte artístico el cuerpo de Moreira se resignifica y permite construir nuevas identificaciones con los contextos artístico, político y sociales que le son propios. A tales efectos, nos preocuparemos por el estudio de la novela, el drama y su transposición al cine a partir del filme realizado en 1924: El último centauro o la epopeya de Juan Moreira de Enrique Queirolo, considerando para este análisis los aspectos constitutivos de la literatura, el teatro y el cine gauchesco.
\end{abstract}

Palabras clave: adaptación fílmica, literatura gauchesca, teatro, cine.

\begin{abstract}
Based on the legend of the Argentine gaucho Juan Moreira, in this article we propose to analyze the different artistic crosses that this body makes from the end of the 19th century to the beginning of the 20th: from the novel to the circus arena and from theater to cinema. We consider that at each intersection and in each new artistic medium Moreira's body is resignified and allows the construction of new identifications with its own artistic, political and social contexts. To this end, we will be concerned with the study of the novel, the drama and its transposition into cinema based on the film made in 1924: The Last Centaur or the epic of Juan Moreira by Enrique Queirolo, considering for this analysis the constitutive aspects of literature, the gaucho theater and cinema.
\end{abstract}

Key Words: film adaptation, gaucho literature, theater, cinema. 


\section{INTRODUCCIÓN}

Entre los símbolos nacionales que identifican a la Argentina encontramos uno de los que más ha despertado laudos, críticas, polémicas y discursos: el gaucho. Sujeto controversial, difícil de clasificar y entender pero que se volvió el paradigma por excelencia de la cultura argentina y que hasta el día de hoy se presenta como un signo identificador de los pensamientos políticos, literarios y culturales de nuestro país. En un estudio reciente de Ezequiel Adamovsky (2019) titulado El gaucho indómito. De Martín Fierro a Perón, el emblema imposible de una nación desgarrada, encontramos una clasificación muy adecuada para dar cuenta del devenir histórico de este lexema y este sujeto. En primer lugar, Adamovsky señala que no es claro el origen de la palabra, pero se registra su uso a partir del siglo XVIII «para designar a cuatreros y vagabundos que se internaban en las profundidades de las campañas para cazar ganado sin fijarse si tenían dueño» (2019: 17). Más adelante, en tiempos de la Colonia y su finalización, el gaucho se asocia con los peones de campo. El tercer momento de su historia, que produce un cambio crucial en su significación, se establece con las Guerras Independentistas. En las luchas contra los ejércitos españoles, el cuerpo social se aúna y las clases populares, en especial aquella que montaba a caballo, toma relevancia: «en este contexto, la palabra gaucho adquirió un sentido ambivalente: comenzó también a hablarse positivamente de esos valientes gauchos patriotas que combatían con heroísmo» (Adamovsky, 2019: 17). Su gloria es tal que muy prontamente el sujeto social se vuelve sujeto literario y construye, de la mano de literatos e intelectuales argentinos, el género gauchesco conformado por la poesía, la novela y el teatro. En relación con este género, el investigador argentino Ricardo Rojas (1948) considera que la épica gauchesca resulta la piedra fundamental sobre la cual se asienta el resto de la literatura argentina, puesto que rescata los orígenes de «nuestra» civilización pampeana. Por su parte, Ángel Rama (1994) destaca el valor social e ideológico de la gauchesca y el modo en que los escritores «gauchos» recrean un habla y crean un público. En uno de los textos fundamentales sobre la literatura gauchesca, Josefina Ludmer (2000) la define como un uso letrado de la cultura popular. Sostiene que «el primer locutor ficticio de la literatura gauchesca es el gaucho en tanto cantor y patriota [...]. Las dos instituciones, ejército y poesía, se abrazan y complementan $[\ldots]$. Surge entonces lo que define de entrada al género gauchesco: la lengua como arma. Voz ley y voz arma se enlazan en las cadenas del género» (Ludmer, 2000: 23). Así, la gauchesca siempre trata de «orillas» y de «alianzas» entre la voz y lo escrito, entre la ley y la no ley.

Hacia fines del siglo XIX el género gauchesco alcanza sus mayores éxitos, en pleno proceso de auge migratorio en la Argentina, que fue incrementado a partir de la década del 80 con la política de Domingo Faustino Sarmiento, puesto que tanto nativos como extranjeros se 
identifican con sus temáticas: gauchos capturados por el Estado que van a la guerra, gauchos desertores que abandonan el ejército y son perseguidos por la ley, gauchos traicionados por sus patrones o por los representantes de la ley, gauchos que pierden sus familias, gauchos que se revelan contra el poder. Como sujeto doble, el gaucho encierra toda la peligrosidad pero también es la fuente de honor y fidelidad entre sus pares, aspectos últimos que en especial concentran dos de los textos más representativos del género gauchesco: el poema Martín Fierro de José Hernández, escrito en 1872 y continuado en 1879, y la novela Juan Moreira de Eduardo Gutiérrez, escrita entre 1879 y 1880. En el poema de Hernández, compuesto por «La Ida» $\mathrm{y}$ «La vuelta», nos encontramos con la historia de un gaucho trabajador al que la injusticia social del contexto histórico lo vuelve un gaucho matrero (fuera de la ley). El escritor argentino Leopoldo Lugones (1916) considera al Martín Fierro como poema épico porque «personifica la vida heroica de la raza con su lenguaje y sus sentimientos más genuinos [...]; porque su poesía constituye bajo esos aspectos una obra de vida integral» (Lugones, 1991: 146). En similares claves narrativas, la novela Juan Moreira cuenta las desventuras de un gaucho que cae en desgracia por su encuentro con la ley, pero, a diferencia de Martín Fierro, Juan es un gaucho que no se adapta al sistema y muere dando pelea hasta el final de sus días. Si bien ambos textos son considerados pilares de nuestra literatura y cultura argentina, a comienzos del siglo XX las aguas se dividieron entre quienes exaltaban la obra de Hernández y desprestigiaban la novela de Gutiérrez. Así lo señala Nicolás Suárez:

Hacia mediados de la década del diez, intervenciones como las de Rojas y Lugones, a las que deben añadirse los resultados de una polémica encuesta acerca del poema de Hernández publicada en la revista Nosotros en 1913, canonizaron el Martín Fierro como una manifestación de la cultura elevada y eso modificó su circulación diferenciándola de la de Juan Moreira. La «separación de las aguas» que, en relación con el Martín Fierro, Prieto detecta «entre la popularidad de un personaje literario y la dignidad del texto que lo proyectaba al imaginario colectivo» $[\ldots]$ funciona también como un parteaguas entre la popularidad de Moreira y la intelectualización de Fierro. En la década del veinte esta situación se acentuó gracias a la aparición de las grandes ediciones del poema, que marcaban una clara distancia respecto de las ediciones baratas que seguían siendo el único canal de circulación impresa para Moreira (2018: 67).

Cabe aclarar que, por esos años, y ante una sociedad absolutamente cosmopolita, se hace necesario producir una uniformidad e identificación y por tal motivo se erige al gaucho literario como símbolo de lo nacional. Y esto es así porque «representa los valores de la libertad, la nobleza de espíritu y el coraje. En su aparición como Juan Pueblo, es el encargado de expresar la voz del cuerpo político. Y, por todo ello, es también el símbolo atemporal de la argentinidad» (Adamovsky, 2019: 12). Ahora bien, el éxito de la gauchesca no culmina en la literatura sino que se hace 


\section{Lía Noguera}

extensivo al teatro, en especial el de fines del siglo XIX, y luego al cine del siglo XX produciendo así la amplificación y diversificación de textualidades del género. Creemos que en cada nueva textualidad y en cada nuevo soporte, los mitos originarios de la gauchesca se resemantizan y cada nuevo contexto de aparición permite hacer oír, leer o ver diferentes voces y cuerpo gauchos. Por tal motivo, nos interesa analizar una voz y un cuerpo que ha atravesado diversas y significativas fronteras (geográficas, culturales, políticas, literarias, teatrales y cinematográficas) y que en cada uno de sus cruces ha dejado una huella fundante: Juan Moreira. Para ello, nos detendremos a continuación en develar el origen de la leyenda, su paso por la novela de la mano de su padre literario, Eduardo Gutiérrez, luego su debut en el circo y el teatro para al final llegar a su último cruce artístico: el cine. Consideramos que con cada nuevo soporte, en cada trasmediación, el mito de Moreira se arraiga más y más en la cultura argentina y permite, a más de un siglo de su aparición, la identificación con la lucha y la persistencia de un pueblo.

\section{1. ¿QUiÉn ES JUAN MOREIRA?}

Tanto su historia real como ficcional ha despertado gran interés en los discursos y debates no solo artísticos, sino, sobre todo, políticos y sociales en la Argentina de finales del siglo XIX y principios del XX. Tal es así que en un artículo de La Prensa, escrito por Juan Álvarez el 10 de abril de 1927 y titulado «Las últimas palabras de Juan Moreira», leemos: «Por lo pronto, paréceme prudente dejar establecido que Juan Moreira murió efectivamente; pues tales y tantas son las inexactitudes tejidas alrededor de su actuación que acaso surja en el futuro la hipótesis de no haber existido jamás y tratarse de un simple mito de origen astronómico» (1927: s. pág.). Los estudios históricos sobre este caso se han encargado de confirmar que efectivamente Juan Moreira existió pero nació con el nombre de Juan Gregorio Blanco y, según consta en los libros de la Iglesia de San José de Flores de Buenos Aires, el 25 de noviembre de 1819 fue bautizado el hijo de Ventura Núñez y Mateo Blanco, mazorquero de Juan Manuel de Rosas a quien el mismo Restaurador de las Leyes mandó a matar. Ahora bien, aquello que produjo la caída en desgracia de este gaucho fue el asesinato del pulpero Sardetti, a raíz de una deuda que este no quiso pagar a Moreira. Este hecho marca la visibilidad de este cuerpo gaucho que constantemente alterna su destino entre los márgenes de la legalidad e ilegalidad estatal. Luego de su derrotero económico, político y social, Juan Moreira encuentra su muerte, tal como lo indica su partida de defunción, el 30 de abril de 1874 en la Localidad de Lobos (supuestamente en La Estrella, casa de placeres en la cual Moreira habría pasado sus últimas horas). Desde el momento de su muerte hasta la actualidad, varias son las fronteras que atraviesa el cuerpo del gaucho Juan Moreira: del prontuario policial, al folletín escrito por Eduardo Gutiérrez entre noviembre de 1979 y enero de 1880 en La Patria Argentina; de la novela a la obra teatral 
coescrita por Gutiérrez y José Podestá en 1884 (primero en versión de pantomima y luego, en 1886, en su versión dialogada); y posteriormente, el cruce fronterizo que realiza hacia la pantalla grande, en primera instancia en 1913, en el filme homónimo de Mario Gallo, hasta llegar a 1973, de la mano de Leonardo Favio. Un cuerpo leyenda, un cuerpo novela, un cuerpo teatral y un cuerpo cinematográfico. Pero también un cuerpo doble que se articula entre la ilegalidad de la oralidad (en su carácter de leyenda popular) y la legalidad de un cuerpo escrito, primero por la letra legal (la policial), luego por la literaria, la teatral y la cinematográfica. Un cuerpo que pasa por varias textualidades y, en cada atravesamiento, se resignifica y produce diversos sentidos.

Sacar a la luz la historia del gaucho Juan Moreira y volverla ficción fue el primer eslabón de una cadena de transposiciones que inicia Eduardo Gutiérrez, escritor y periodista argentino, que escribe esta obra en la sección de «Dramas policiales» del periódico de su familia. Aquí Gutiérrez nos presenta la historia de Moreira, quien, tras reclamar ante el juzgado de paz que el pulpero Sardetti le pague su deuda y la ley no fallar a su favor, decide hacer justicia por mano propia. El gaucho Moreira mata al pulpero, acto que lo obliga a escapar del peso de la ley, abandonando así a su familia: Vicenta y su hijo Josecito. Durante su ausencia, Vicenta es engañada e informada de que Moreira había muerto. Ella pierde sus tierras y a fin de salvar su situación económica y protegerse de las amenazas y deseos amorosos del Juez de Paz, se casa con su compadre. Mientras tanto, Moreira se resguarda entre los indios, sigue peregrinando por tierras pampas, se asocia a diferentes partidos políticos pero en todo momento sigue siendo perseguido. Encuentra su muerte a traición, por la espalda como no matan los gauchos, en una casa de placeres, pero hasta el final de sus días continúa dando batalla. Así, basándose en un prontuario policial y ficcionalizando algunos aspectos de la leyenda de este gaucho, Gutiérrez construye un héroe, pero su novedad es que es un héroe popular. El crítico literario argentino Carlos Gamerro afirma que «una y otra vez, Gutiérrez destaca los atributos que lo ponen por encima del común de los mortales, "su hercúleo brazo", "su hercúleo pecho", "su pujanza sobrehumana" [...]; pelea solo contra partidas cada vez más numerosas y las derrota a todas [...]. Moreira es el gaucho matrero vuelto superhéroe; su lujosa vestimenta, un traje de Superman» (2016: 203).

A la vez, con esta acción escritural de Gutiérrez de la leyenda del gaucho matrero, se logra perpetuarlo en la historia de la alta cultura, pero también, y sobre todo, de la cultura popular. Porque, y tal como lo han señalado diversos estudios (Prieto, 2010; Chicote, 2013; Gamerro, 2015, entre otros), la visibilización literaria de Juan Moreira produce un «boom editorial» que no solo explica un fenómeno económico, sino sobre todo un proceso de encauce político y cultural en un contexto finisecular de plena modernización y civilización. Con el Moreira, ese personaje «a medio hacer, un golem gaucho» (Gamerro, 2015: 208), se inicia una serie 


\section{Lía Noguera}

literaria de temática gauchesca que conquista a una gran cantidad de lectores -cercanos al mundo rural pero también pertenecientes a la ciudad- hacia fines del siglo XIX y principios del XX. Un fenómeno que puede explicarse (Prieto, 2006: 97-98) a partir de tres funciones:

(1) despierta la imaginación del hombre de pueblo y concreta, literariamente, una venganza;

(2) proporciona una estructura de consolación a partir de un personaje «superhombre»;

(3) propone una catarsis del descontento.

En este sentido, la literatura popular de este período concreta un abanico de respuestas para una población caracterizada por una creciente multiculturalidad y que muestra una particular estructura de sentimiento: la dislocación de un sujeto social ante un contexto de incipientes cambios. Cabe señalar que gran parte de las publicaciones que se produjeron en ese período se encuentran en la «Biblioteca Criolla» que pertenece al legado de Robert Lehmann-Nitsche y desde 1939 se halla en el Instituto Iberoamericano de Berlín. Con esta Biblioteca, «lo criollo pasa ahora a designar la nueva conformación social de la sociedad rioplatense de principios del siglo XX, en la cual la prensa periódica, las publicaciones populares, el teatro, y posteriormente el cine, serán los nuevos forjadores de identidad de las poblaciones urbanas y rurales» (Chicote, 2013: 32).

\section{UN GAUCHO INVADE LA ARENA DEL PICADERO}

Corría el año 1884 cuando un día, en el vestíbulo del Teatro Politeama de Buenos Aires, Alfredo Cattaneo (representante de la compañía de los Hermanos Carlo) le propone a Eduardo Gutiérrez que adapte su novela Juan Moreira en versión mimodrama para que esta compañía la represente antes de su despedida de Buenos Aires. Gutiérrez acepta la propuesta a sola condición de que el personaje de Moreira sea interpretado por el actor José Podestá, que por aquellos días trabajaba en el Teatro Humberto Primo con su payaso Pepino 88 y su caballo. Así, y tras este primer "acuerdo literario-dramático», se estrena Juan Moreira el «2 de junio de 1884, como fin de fiesta y para cerrar el espectáculo circense de los hermanos Carlo» (Pellettieri, 2002: 102). Ante el éxito obtenido, la pantomima fue representada en tres ocasiones más, ya que la compañía de los Carlo inicia una gira a Río de Janeiro, experiencia a la cual se suman los Podestá. De regreso a la Argentina, los Podestá se asocian con Alejandro Scotti y compran en la ciudad de La Plata el Pabellón Argentino, «un circo con cuatro cabriadas de madera, cubierto de lona, situado en las calles 7 y 56, en el que debutan el 11 de enero de 1885 bajo el nombre «Podestá-Scotti»» (Podestá, 2003: 55). Así, un segundo acuerdo se produce, ahora económico-artístico, que implica una posterior reaparición de Juan Moreira, pero ahora en versión dialogada. Así, el 10 de abril de 1886, la compañía estrena en Chivilcoy el Juan Moreira hablado y 
el éxito es rotundo. De este modo lo relata José Podestá en sus memorias: «El público, acostumbrado a ver pantomimas a base de vegijazos, y sainetes con finales en que el garrote de paja resolvía todas las intrigas, se halló de buenas a primeras con algo que no esperaba, y, de sorpresa, en sorpresa, pasó al más vivo interés y de éste al entusiasmo demostrado al final de una gran ovación» (Podestá, 2003: 57).

Con el pasaje de novela a teatro, Juan Moreira marca el inicio del campo teatral argentino, puesto que permite la sistematización de una poética textual de temática gaucha, la visibilización de una poética actoral (la popular), la invención de un público y la aparición del teatro como práctica social. A partir de su éxito, la arena del circo en el cual se representaban estas obras luego de los espectáculos circenses, se llena de nuevos gauchos: Juan Cuello, Julián Giménez, Martín Fierro, Calandria, entre otros, y poco a poco abandonan el picadero y pasan a los teatros con sala a la italiana, no solo en la capital del país, sino también en sus giras nacionales. Además, con ese estreno se produce un acuerdo estético, social y político que concentra los paradigmas principales que constituyen la estructura de sentimiento de la Argentina de fines del siglo XIX en su proceso de enculturación, posterior al surgimiento del Estado Moderno argentino. Asimismo, y en relación con la transposición teatral, observamos que existe en ella una condensación de la historia y de los niveles de prehistoria presentes en la novela de Eduardo Gutiérrez, proponiendo así una escritura económica que recala en las matrices de heroicidad de Moreira. A la vez, en el drama se suprime casi totalmente el universo amoroso y aquello que se privilegia es el espacio público de este gaucho. Así, en la versión teatral, el desacuerdo que permite la aparición del cuerpo de Moreira en el plano de la historia responde únicamente a un desacuerdo económico: la deuda de Sardetti y su incumplimiento de pago. Razón por la cual, consideramos que el drama singulariza el cuerpo de Moreira, lo inscribe en el orden de lo público y posibilita, en ese gesto, un alto grado de empatía e identificación con sus espectadores. Porque con el Moreira teatral (y a partir de la procedencia circense de los actores que representan la obra y el delineamiento de aquello que constituirá la poética del actor popular) se pone en escena un cuerpo-destreza y un cuerpoacción que busca a cada paso recuperar su honra y reivindicarse socialmente. Pero, como afirma Rodríguez, «esta reparación simbólica de ningún modo excluía la función de entretener» (1999: 24). A la vez, y como nuevo mito que se inscribe a partir del uso del cuerpo de Moreira por parte de José Podestá - puesto que, y a modo de elemento expansivo, se «mitifica» al propio actor-, se habilita el encuentro y circulación de los bienes culturales propios de los sectores populares y la cultura de elite de finales del siglo XIX. Sabemos que destacados nombres de la high life porteña «invadieron nuestro modesto circo y aplaudieron a nuestros modestos gauchos» (Podestá, 2003: 71). De esta manera, y a raíz del éxito de su Juan Moreira, la elite porteña masculina, que gustaba ver teatro culto 


\section{Lía Noguera}

junto a sus esposas, reconoce el valor de la pieza pero también el valor de la propia actuación de Podestá, proponiendo así una doble visibilización: la del cuerpo del gaucho Moreira y la del cuerpo de Podestá como actor. Con su Moreira, José Podestá gana en reconocimiento, amplifica las representaciones de la historia de este gaucho, adapta y crea otras versiones de los clásicos de la literatura gauchesca y participa de los festejos del Centenario que contaron con la presencia, entre otras celebridades, de la Infanta Isabel de Borbón.

\section{MOREIRA VA AL CINE}

A pocos meses de la presentación del cinematógrafo de los hermanos Lumière en 1895, Enrique Mayrena trajo a Buenos Aires la primera cámara de cine que se dio a conocer con el nombre de vivomatógrafo y que tuvo su estreno en un local de la calle Florida de Buenos Aires. Solo algunos años después el cuerpo de Juan Moreira invade esta nueva tecnología. La primera visibilización cinematográfica de este gaucho tiene como registro el año 1902, momento en el que se filma El Pericón Nacional. Esta cinta se encontraba perdida y fue hallada recientemente en el Instituto Nacional de Estudios de Teatro de Buenos Aires. De la exhaustiva investigación que se está realizando sobre ese rollo de nitrato de $35 \mathrm{~mm}$. que dura 7:30 minutos, Laura Mogliani (2019: s. pág.), directora del INET, infiere que el filme silente coincide con El Pericón Nacional. Para ello, se basa en los estudios que brindan datos sobre este filme: el libro de César Maranghello Breve Historia del Cine Argentino y el de Guillermo Caneto y otros autores titulado Historia de los primeros años de cine en la Argentina. Además, en esos estudios, según Mogliani, se corrobora la fecha del estreno de la película de Alberto B. Martínez, el 16 de mayo de 1902, y su lugar de exposición fue el Cinematógrafo del Teatro Nacional. Asimismo, afirma que:

el pericón nacional es una danza que en 1889 se incorporó a las representaciones de Juan Moreira en reemplazo del gato en la secuencia costumbrista del segundo acto. Al fin de una de las representaciones de Juan Moreira en Montevideo, José Podestá conoció a Elías Regules (padre), quien le sugirió el cambio del gato por el pericón, una danza que se bailaba en la campaña uruguaya, desconocida en la Argentina, y que Regules consideró «más apropiada y de mayor efecto para la fiesta campestre del drama» [...], lo que señala que el objetivo del cambio fue el aumento de la espectacularidad escénica (2019: s. pág.).

Once años más debe esperar el gaucho Moreira para reaparecer en la pantalla, puesto que recién en 1913 Mario Gallo dirige su Juan Moreira. A esta transposición de la novela de Gutiérrez le siguen: El último Centauro o la epopeya de Juan Moreira (1924) de Enrique Queirolo, Juan Moreira (1936) de Nelo Cosmi, Juan Moreira de Moglia Barth y, por último, Juan Moreira (1973) de Leonardo Favio. A fin de dar cuenta de nuestro objetivo principal, evidenciar los cruces y analizar las resemantizaciones del mito 
moreirista, a continuación analizaremos el filme realizado por Enrique Queirolo. Para ello, no pretendemos analizar los aspectos que refieren a la fidelidad o no del filme en relación con la obra dramática y literaria, sino que con Wolf entendemos la transposición a partir de la paradoja que el investigador elige para explicar este fenómeno: «cómo olvidar recordando». En palabras de Wolf:

Cómo olvidar recordando quiere decir que ese origen no puede eliminarse como si jamás hubiera existido, pero que tampoco puede estar totalmente presente porque eso orillaría el peligro de anular la voluntad misma de la transposición. Por definición, el texto literario tomado para hacer con él un filme es deformado o alterado al ser transpuesto a otro código y otro lenguaje difuso, aunque haya quedado enterrado bajo múltiples capas de tierra, depositado en el fondo como un sedimento, como un resto o prueba de lo que fue más de lo que pudo haber sido (2001: 78).

A partir de esta definición entendemos que, en primer término, una transposición es más que el mero traspaso de materias significantes no homogéneas de un soporte a otro, puesto que ella constituye una estrategia de intervención hermenéutica, una política de lectura y una interpretación crítica. En segundo término, importa un cuestionamiento a la intangibilidad de la noción de origen y la apertura a la de infinito comienzo, a la idea de que lo que «empezó puede volver a empezar» desde su continua reproducción, interrogación y reexaminación (Grüner, 2001). Entonces, entendido desde esta perspectiva, el fenómeno transpositivo demanda que se le otorgue el carácter de «diálogo» con otros textos, ya sean anteriores o simultáneos, que se lo piense como una «versión» entre tantas otras imaginables $-\mathrm{y}$, por ello, que se comprenda su condición provisoria, dable de ser refutada, completada o ignorada por otros trabajos- y que se renuncie a la búsqueda de «fidelidad», tal como pretendemos hacer en nuestro análisis de la película de Enrique Queirolo.

\section{De GaUCHOS Y CENTAUROS}

La Argentina de comienzos del siglo XX se caracterizó, por un lado, por la asunción de los gobiernos radicales de Hipólito Yrigoyen (19161922 y 1928-1930), presidente que por primera vez fue elegido por el voto universal que sancionó la ley electoral de 1912; por otro lado, por los efectos que la Primera Guerra Mundial (1914-1918) trajo a nuestro país. Con respecto a las consecuencias de la Primera Guerra Mundial es necesario destacar el gran impacto que tuvo en todos los planos de la Argentina del nuevo siglo: se presentaron dificultades en el comercio exterior, las inversiones de capitales extranjeros comenzaron a retraerse, se produjo una paulatina inflación y los salarios laborales disminuyeron a la vez que se incrementó la desocupación. Esta situación produjo que las huelgas se multiplicaran y que alcanzaran su momento más álgido entre los 


\section{Lía Noguera}

años 1917 y 1919, momento en el cual se produce la Semana Trágica (entre el 7 y el 14 de enero de 1919). Esta, junto con los sucesos acaecidos en Santa Cruz conocidos como La Patagonia Rebelde, fue unas de las represiones más importantes que sufrió el movimiento obrero argentino por los reclamos que postulaban ante el gobierno de Yrigoyen. Las huelgas fueron disipadas mediante mecanismos coercitivos y movimientos paramilitares cuyo saldo se estimó en cientos de muertos y desaparecidos. Por estos años el campo artístico también se vio afectado con dos huelgas: una, entre el 6 y el 19 de mayo de 1919; otra, entre mayo y junio de 1921. Luego de estos incesantes conflictos y variadas manifestaciones por parte de los sectores obreros, culminó la primera presidencia de Yrigoyen, a quien lo sucede Marcelo Torcuato de Alvear. Durante los años de Alvear, el yrigoyenismo comenzó a rearmarse: desarrolló una red de comités y fortaleció la imagen mítica del caudillo (Romero: 2001). En 1928 Hipólito Yrigoyen alcanzó la reelección presidencial pero no logró culminar su mandato debido a que fue depuesto por el primer golpe de estado del periodo constitucional.

Otra de las consecuencias que produjo la Primera Guerra mundial se relaciona con el campo cinematográfico. Si el cine de los primeros tiempos en nuestro país siguió las coordenadas del cine europeo a partir del film d'art, con el impacto de esta Guerra y la imposibilidad de importación de filmes desde el viejo continente, se produce una irrupción de la cinematografía norteamericana. Esto ocasionó un cambio en la estética que se resume en una proliferación en la composición técnica del cine argentino, dejando así como «pasadas de moda» las formas iniciadas para los filmes de ficción. Y si hablamos del cine de ficción, debemos señalar que la cinematografía de las primeras décadas del siglo XX se articuló a partir de un polo positivista que se refugió en el cine de noticiario o actualidades, y un polo nacionalista que encontró su lugar preferencial entre los filmes de ficción, «nacido en la euforia patriótica del primer centenario de la independencia» (Cuarterollo, 2010: 7). Si, como explica Cuarterollo (2010), las ideas imperantes del positivismo constituyeron un conjunto de filmes caracterizados por el avance tecnológico y los diversos paradigmas asociados a la idea de progreso, y que representaba a los sectores de la elite Argentina de aquellos tiempos, que destacaron el espacio urbano y produjeron una invisibilización del pueblo, el ideario nacionalista impregnado en los filmes de ficción constituyó un abanico de temas y problemas que se vincularon con los sectores subalternos, rescatando así el espacio del campo, la representación del pueblo y la exaltación del criollismo.

Del conjunto de películas de ficción producidas en las primeras décadas del siglo XX, muchas de ellas responden a la categoría de filmes biográficos, en la cual se inscriben las diversas versiones cinematográficas de Juan Moreira. Ana Laura Lusnich, en su artículo «El formato biográfico en el cine argentino: una mirada institucional», propone una distinción en 
esta categoría, discriminando, por un lado, aquellos que se inscriben en la representación de las biografías de héroes históricos (destacadas figuras del ámbito político, cultural, militar y que marcaron un hecho histórico concreto); por otro lado, las biografías que se relacionan con la representación de la vida de héroes populares (personalidades destacadas del campo artístico, deportivo y de la política no oficial). Considerando que nuestro corpus de análisis se relaciona con las biografías de héroes populares, nos interesa destacar las características de estos filmes, siguiendo los aportes teóricos de Lusnich (2001) y que podemos sintetizar del siguiente modo:

-Temporalidad: articulada a partir de tres momentos del héroe, pasado, presente y futuro, de los cuales el primero es vivido como fuente de felicidad, el segundo como desdicha y el tercero como incertidumbre.

-Espacialidad: periplo geográfico caracterizado por un recorrido circular y que muestra paisajes del interior de la Argentina.

-Procedimientos visuales y sonoros: el flashback, la cabalgata visual, la utilización de planos generales y primeros planos, la amplificación de la banda de sonido, aspectos que intervienen en la legitimación del héroe y lo distinguen del entorno social.

- Clausura del relato: el destino final del protagonista se traduce en la muerte y/o en la privación del hábitat y de la tierra de origen.

En este sentido, las biografías de héroes populares (y en especial las de Juan Moreira) consolidan un modo de representación legitimador de las historias de cuerpos que solo a partir de su encuentro con el poder legal se vuelven visibles no solo en la Historia, en la literatura y en el teatro, sino también en el universo cinematográfico, tal como lo observamos en la versión cinematográfica de Enrique Queirolo. Este director argentino, en 1923, filmó su película en las provincias argentinas de Chaco y Córdoba y la estrenó en Rosario (provincia de Santa Fe, Argentina) al año siguiente. Esta película silente contó con el guion del creador del folletín de Juan Moreira, Eduardo Gutiérrez, y un elenco conformado por Carlos Perelli (Juan Moreira), Ángela Tesada (Vicenta), Pedro Constanza, Carlos Torres Funes, Milagros de la Vega, Alberto Anchart y Esteban Peyrano. El filme se inicia con un plano general del espacio del campo y luego una cita del escritor Elías Regules (hijo de quien había recomendado cambiar el baile del gato por el pericón en la versión teatral y que mencionamos previamente), quien escribió las obras teatrales Martín Fierro (1889) y El entenao (1892). Las palabras que se refieren a la última obra nos informan:

Soy el gaucho que retruca

que generoso y altanero

el que saluda al pampero

con el sombrero en la nuca 


\section{Lía Noguera}

el que peliando se educa

y aprende a golpe y revés.

El perseguido del juez

el entenao de esta tierra,

soy el primero en la guerra

pa ser último dispués.

En este primer gesto vemos cómo el filme comienza a evidenciar una cadena de intertextualidades, en este caso, con el universo de la dramaturgia gauchesca, aspectos que se intensifican con citas literales en el filme a la obra Martín Fierro. Tal es el caso de la famosa frase «Va cayendo gente al baile» que se menciona en relación con los invitados que arriban a la fiesta de bautismo del hijo de Moreira, Josecito. Frase que suma en la obra de Hernández un eslabón más en la cadena de muertes de Fierro y que en el filme de Queirolo funciona como anticipadora del futuro funesto que atravesará a nuestro héroe gaucho. En un profundo y pertinente estudio sobre este filme, Nicolás Suarez postula estas relaciones con el texto de Hernández como una martinfierrización de la figura de Moreira en el filme de Queirolo y explica que:

entiendo por martinfierrización de Moreira un proceso que incluye dos movimientos: primero, una disolución del carácter rebelde de Moreira en el espíritu conciliatorio de la Vuelta; y luego, su monumentalización según el espíritu épico de las lecturas del Martín Fierro surgidas en torno al Centenario. Ese intento de prestigiar a Moreira martinfierrizándolo se efectúa, en el filme de Queirolo, a través de una serie de procedimientos formales que abarcan diversos aspectos de la composición de la obra, como los intertítulos, la construcción del espacio, la planificación y los paratextos (2018: 69).

Creemos que esa dislocación del carácter rebelde propio del mito y el personaje de Moreira que se representa en el filme no solo se refiere a una asociación con el personaje de Fierro, sino a toda la cadena de personajes dramáticos gauchescos que se abren luego de Juan Cuello (1890), de Luis Mejías y José Podestá, y que culmina con Calandria $(1896)^{1}$, de Martiniano Leguizamón. En ese abanico de cuerpos y voces gauchescos se produce un disciplinamiento del gaucho pero se mantiene su honra y su valor. Además, la apelación al universo gauchesco que rodeó a la obra dramática de Gutiérrez y Podestá permite evidenciar los procedimientos transescriturales que el propio autor de la novela y la obra dramática realiza en el filme a fin de consolidar la solidaridad de signos y permitir su

\footnotetext{
${ }^{1}$ Texto fronterizo que establece la clausura del género gauchesco y el inicio de la poética nativista en el teatro, y en el cual observamos cómo se produce la incorporación del gaucho al sistema estatal. A partir del indulto de Calandria, este cuerpo ilegal se legaliza: de ser gaucho matrero pasa ser «criollo trabajador». Así, con Calandria «el héroe se vuelve inofensivo y el conflicto social irreconocible» (Mogliani, 2002: 177).
} 
identificación con este universo en un contexto en el cual se busca la exaltación de la heroicidad por parte de un personaje popular.

Así, y sentadas las bases del lugar en el que transcurren las acciones y con una breve presentación de las características principales de quién es el héroe del filme, comienza esta epopeya articulada en XV actos, y que en todo momento busca la exaltación de la nobleza de este gaucho a pesar de su caída en desgracia. Desgracia que como en la novela y en la obra teatral se inicia por un enfrentamiento de legalidades, la del gaucho que cree en la fuerza de la palabra oral y la del extranjero Sardetti quien se ampara en las leyes de la palabra escrita (o no escrita, en este caso) a fin de no pagar la deuda que contrajo con Moreira. Es con esta traición al valor del contrato, que se sella con un apretón de manos, como comienza el periplo de este héroe popular, que continúa -tal como en sus hipotextos- con los asesinatos de Sardetti y el alcalde, la pérdida del hogar, su esposa y su hijo, el cambio de nombre, la imposibilidad de mantenerse oculto y por último la muerte, también a traición, en la casa La Estrella. Así, en este itinerario del héroe, en el cual la cámara privilegia las escenas en espacios abiertos, el punto de vista se posiciona desde un espectador conocedor de la historia de Moreira y los planos generales, medios y primeros son las características formales del filme, nos interesa detenernos en la historia de Vicenta y Moreira como así también en la representación que la película hace de esta mujer. A diferencia de la versión teatral de Juan Moreira, en la cual lo amoroso es elidido -y en ese sentido, el guionista (Eduardo Gutiérrez) se basa más en la novela que en su adaptación teatral realizada junto con José Podestá-, el filme retoma procedimientos melodramáticos y los profundiza como así también intensifica el lugar de penar de Vicenta. En este género, y tal como lo explica Eduardo Russo, encontramos que:

el espacio de la mujer está en riesgo permanente, y toda virtud es amenazada. El hombre del melo, por su parte, es un hombre herido, desprovisto de plenitud. Los villanos sostienen un plus de maldad más allá de cualquier motivación posible. Los espectadores saben todo esto y mucho más: conocedores de las razones últimas de estas penurias, también pueden compartir aquello que sienten sus protagonistas (1998: 27).

En este sentido, y siguiendo estos preceptos del género, observamos que el filme de Queirolo elige singularizar en varios momentos la imposibilidad de felicidad de la pareja amorosa: Juan y Vicenta. Si bien ellos logran su unión a partir de su enlace matrimonial, tanto el Sargento como el compadre de Moreira y los penares económicos hacen que se rompan sus lazos y terminen separados. Recordemos que luego de los dos primeros asesinatos de Moreira, él debe abandonar el espacio familiar a fin de escapar de la ley de la justicia. En esta huida, Vicenta queda «a la buena de Dios» y es la reconstrucción de ese pasado en el cual una de las escenas del filme problematiza. A partir del encuentro de Vicenta con el amigo de 


\section{Lía Noguera}

Moreira, Julián, ella, mediante diversos flashbacks, pone en conocimiento a sus interlocutores (Julián y los espectadores) sobre su pasado funesto. Sin dinero, con el rancho quemado y con su hijo pequeño, recorre la inmensidad del campo a fin de conseguir un amparo para su situación, luego de rehusarse a ser ayudada por Giménez. Pero el tiempo pasaba y su situación de desdicha económica y sentimental se acrecentaba, razón por la cual accede a ser protegida por la mano (y el cuerpo) de Giménez, luego de que él le confirmara que Moreira había muerto en una partida. Los primeros planos que se realizan sobre ella, la alternancia del tiempo de la enunciación entre un pasado reciente de penas y un presente estable, singularizan este universo femenino y lo vuelven visible (aspectos solo mencionados en la novela y directamente omitidos en la obra teatral). Asimismo, y a fin de acentuar esta mostración, su relato se cuenta y se representa dos veces, puesto que cuando Giménez se encuentra con Moreira, le narra la historia de Vicenta, haciendo nuevamente uso del flashback pero continuando desde el punto de vista de Vicenta.

Otro de los aspectos que nos interesa señalar es que el filme de Queirolo postula un archivo de las mitologías gauchescas que circularon en la literatura y el teatro del siglo XIX y principios del XX. Por tal motivo, y siguiendo a Carlos Monsiváis (1992), nos interesa analizar una de las mitologías que este autor menciona en relación con la época del cine de oro mexicano: las atmósferas. Es decir, el conjunto de espacios, celebraciones, prácticas y motivos que el cine representa de la cultura popular a fin de encontrar su significación específica. De esta manera, en el filme de Queirolo encontramos las siguientes atmósferas:

-La pulpería: lugar de encuentro entre hombres en donde el alcohol, el ocio y el divertimento son la moneda corriente y también el espacio propicio en el cual se debaten los destinos de las personas.

-El rancho familiar: reducto de los amores y las pasiones «en buena fe» que separa, mediante un delicado equilibrio, la desmesura del gaucho y le posibilita a soñar con ese pasado de paz que alguna vez tuvo. A la vez, y en su destrucción por la ley del estado, sintetiza las huellas de una barbarie que se pretende «civilizada», y en esa misma pretensión, destruye las características de aquello que alguna vez fue, un locus amoenus.

-Las fiestas familiares: los casamientos y bautismos que se asocian con una vida cristiana de los hombres y mujeres en el campo y que son representados como un broche de oro estelar para la configuración de los amores en buena ley, la de Dios, y que santifica a los sujetos y a las relaciones que los emparenta.

-La alcadía: representación de la política en el cual la Ley del Estado opera por privilegios y establece un mecanismo de prácticas de un control detallado de los cuerpos bárbaros, los gauchos, que no se sublevan ante su poder. 
-El campo: «el paisaje idílico, el pueblo. La gran escenografía donde son una y la misma cosa el primitivismo y la pureza» (Monsiváis, 1992: 15), pero en donde esta última se corrompe a causa de una legalidad estatal que se opone a la legalidad de los hombres y mujeres del campo.

-El entretenimiento popular: la riña de gallos, las apuestas, las corridas de caballos, como prácticas cotidianas de una clase que apuesta por la idea de comunidad y que privilegia el tiempo no reglado en pos de replegarse ante un presente que se vuelve cada día más hostil.

-La amistad: como valor que no es intercambiable por ningún material económico, que rige las acciones y que apuesta, aun sabiendo que va a perder, por la defensa de las causas justas. Porque, «¿qué es la amistad sino una proximidad tal que no es posible hacerse ni una representación ni un concepto de ella?», se pregunta Agamben (2016: 43) en un artículo en el que problematiza sobre este tópico. La amistad es una co-presencia, un co-sentir junto a otro que no es otro yo, sino un devenir otro de lo mismo. Porque «los amigos no comparten algo (un nacimiento, una ley, un lugar, un gusto): ellos están com-partidos por la experiencia de la amistad. La amistad es el compartir que precede a toda división, porque lo que tienen que repartir es el hecho mismo de existir, la vida misma. Y lo que constituye la política es esta repartición del objeto, este co-sentir original» (Agamben, 2016: 49).

-El baile y la música: cuerpos que al ritmo del pericón y el malambo se entretejen entre guitarreadas a fin de exponerlos, por un lado, como bienes simbólicos y materiales de esta cultura gauchesca; por otro, como la manifestación del cuerpo en acción y en presencia que se territorializa en un espacio específico («Aquí me pongo a cantar») y resiste a los embates de aquellos que pretenden «domarlos».

-Los enfrentamientos: donde, por un lado, los cuerpos subalternos (gauchos y extranjeros) se baten entre sí a fin de dignificar el nombre de aquel que fue mancillado; por otro lado, el encuentro entre cuerpos subalternos y cuerpos del poder, en el cual, si en el primero se bate cara a cara y con cuchillos, en el segundo se realiza mediante armas y muchas veces a espaldas del enemigo. Mediante el enfrentamiento se ponen en juego el sistema de legalidades que operan entre dos universos irreconciliables: el de la supuesta barbarie y el de la supuesta civilización.

En síntesis, mediante la biografía de un héroe popular e inscribiendo su discurso en los paradigmas nacionalistas de la Argentina de principios de siglo XX y mostrando un archivo de atmósferas gauchescas, El último centauro... propone un reposicionamiento en el panteón de las voces y los 


\section{Lía Noguera}

cuerpos gauchescos que cimentaron las bases de la construcción identitaria nacional a dos décadas del centenario nacional. Con el filme, Queirolo enaltece el gesto patriota y proporciona una cadena de nuevos signos que rodean al héroe popular Juan Moreira. Por ello, luego de su asesinato, y como laudo final que no se encuentra en la novela y tampoco en obra teatral, el filme nos muestra el peregrinaje del cuerpo de Moreira hacia su morada final, acompañado por los pocos «que se atrevieron a desafiar la justicia» (tal como lo dicen los títulos del final), el monumento al gaucho, la bandera argentina flameando en un inmenso cielo y estas palabras: «Con el último centauro se enterró la soberbia, la audacia y el temerario valor del Gaucho Señor en nuestras pampas».

\section{BibliOgRAFÍA CITADA}

Adamovsky, Ezequiel (2019), El gaucho indómito. De Martín Fierro a Perón, el emblema de una nación desgarrada, Buenos Aires, Siglo XXI.

Álvarez, Juan (1927), «Las últimas palabras de Juan Moreira», La Prensa, s. pág.

BORGES, Jorge Luis (1980), «La poesía gauchesca», en M. T. Gramuglio y B. Sarlo (eds.), Martin fierro y su crítica, Buenos Aires, Centro Editor de América Latina, págs. 95-109.

Chicote, Gloria (2013), «De gauchos, criollos y folklores: los conceptos detrás de los términos», Anales de Literatura Hispanoamericana, 42, págs. 19-34

[En

línea: http://dx.doi.org/10.5209/rev_ALHI.2013.v42.43652.

Fecha de consulta: 20/04/2020].

Cuarterolo, Andrea (2009), «Los antecedentes del cine político y social en la Argentina (1896-1933)», en A. L. Lusnich y P. Piedras (eds.), Una historia del cine político y social en Argentina. Formas, estilos y registros (1896-1969), Buenos Aires, Nueva Librería, págs. 145-172.

Cuarterollo, Andrea (2010), «El arte de instruir deleitando. Discursos positivistas y nacionalista en el cine argentino del primer Centenario», Revista Iberoamericana, 39, págs. 197-210 [En línea: https://www.iai.spk-

berlin.de/fileadmin/dokumentenbibliothek/Iberoamericana/39. 2010/39_Garrigan.pdf. Fecha de consulta: 15/04/2020].

Gamerro, Carlos (2016), Facundo o Martín Fierro. Los libros que inventaron la Argentina, Buenos Aires, Sudamericana.

GrüNER, Eduardo (2001), El sitio de la mirada, Cali, Norma.

LUDMER, Josefina (2000), El género gauchesco. Un tratado sobre la patria, Buenos Aires, Perfil.

LugOnES, Leopoldo (1991), El payador y antología de poesía y prosa, Caracas, Biblioteca Ayacucho.

LusNich, Ana Laura (2007), El drama social-folclórico. El universo rural en el cine argentino, Buenos Aires, Biblos. 
La transposición de la literatura y el teatro argentino

LusNich, Ana Laura (2001), «El formato biográfico en el cine argentino: una mirada institucional» [En línea: http://www.caia.org.ar/docs/Lusnich.pdf. Fecha de consulta: 10/04/2020].

Mogliani, Laura (2002), «Concepción de la obra dramática del nativismo», en O. Pellettieri (dir.), Historia del teatro argentino en Buenos Aires. II: La emancipación cultural (1884-1930), Buenos Aires, Galerna, págs. 175-184.

Mogliani, Laura (2019), «El film silente Pericón Nacional, valioso rescate del Archivo Audiovisual», Instituto Nacional de Estudios de Teatro. Noticias [En línea: https://inet.cultura.gob.ar/noticia/el-film-silentepericon-nacional/. Fecha de consulta: 15/04/2020].

Monsiváis, Carlos (1992), «Las mitologías del cine mexicano», Inter medios, 2, págs. 12-23.

Pellettieri, Osvaldo (2002), «Microsistema de la gauchesca teatral», en O. Pellettieri (dir.), Historia del teatro argentino en Buenos Aires. II: La emancipación cultural (1884-1930), Buenos Aires, Galerna, págs. 100130.

Podestá, José J. (2003), Medio siglo de farándula. Memorias de José J. Podestá, Buenos Aires, Galerna.

Prieto, Adolfo (2006), El discurso criollista en la formación de la Argentina moderna, Buenos Aires, Siglo XXI.

Rama, Ángel (1994), Los gauchipolíticos rioplatenses, Buenos Aires, Centro Editor de América Latina.

RODRíGuEZ, Martín (1999), «El inmigrante italiano y la gauchesca», en O. Pelletieri (ed.), Inmigración italiana y el teatro argentino, Buenos Aires, Galerna, págs. 17-34.

Rojas, Ricardo (1960), Historia de la literatura argentina. II, Buenos Aires, Ediciones Kraft.

Romero, Luis Alberto (2007), Breve historia contemporánea de la Argentina, Buenos Aires, FCE.

Russo, Eduardo (1998), «Persistencia del melodrama», El amante, 75, págs. 27-28.

Wolf, Sergio (2001), Cine/Literatura. Ritos de pasaje, Buenos Aires, Paidós. 